\title{
Epidemiological Profiling of Mechanical Ocular Trauma and Analysis Using Proposed New Classification for Ocular Adnexal Injuries
}

\author{
(1) Abha Shukla, (1) Manisha Singh, (1) Ashish Garg \\ Department of Ophthalmology, Gajra Raja Medical College, Gwalior, India
}

\begin{abstract}
Objectives: Mechanical ocular trauma can result in wide spectrum of injuries with varying levels of severity. A complete ophthalmic examination is important to achieve a thorough evaluation and provide optimal management. The ocular adnexa play a significant role in the protection of the globe via various mechanisms. Open and closed globe injuries directly affect the visual outcome. Although adnexal injuries may not affect the vision directly, they can lead to severe ocular morbidity in terms of a cosmetic blemish, watering, a long healing period, severe complications, or permanent disfigurement. Currently, there is no appropriate classification of adnexal injuries. This study examined the causes, and effects of adnexal injuries to prepare a new classification system for adnexal injuries.

Methods: A retrospective study of ocular injuries was conducted at a tertiary care center in Gwalior, India. The data of 600 mechanical ocular trauma patients were analyzed and the demographic details, mode of injury, type and sub-type of ocular injury were recorded. The injuries were divided into open and closed globe injuries using the Birmingham Eye Trauma Terminology classification system. Adnexal injuries were categorized by type and sub-type using a proposed classification system.

Results: Among the 600 cases, there were 34 closed globe injuries, 26 open globe injuries, and 540 adnexal injuries. Only $10 \%$ of the cases could be classified using the conventional classification system.

Conclusion: The existing classification system is not optimally comprehensive; the majority of the cases could not be categorized. A more detailed framework of classification of adnexal injuries will facilitate better assessment and management. Keywords: Adnexal injury, adnexal injury classification, Birmingham Eye Trauma Terminology classification system, mechanical ocular trauma, open and closed globe injuries
\end{abstract}

\section{Introduction}

Advances in science and technology have enabled greater distinction among types of ocular trauma. Mechanical ocular trauma is a major cause of preventable blindness and visual impairment worldwide (I). It can result in wide spectrum of injuries, including globe injuries, adnexal injuries, and other associated injuries with a severity that can range from a relatively superficial abrasion to damage that can threaten vision. The ocular adnexa play a major role in the protection of the globe as a mechanical defense mechanism as well as through tear film maintenance and tear drainage, eyelid gland secretion, and local active immunity mechanisms. A mechanical

How to cite this article: Shukla A, Singh M, Garg A. Epidemiological Profiling of Mechanical Ocular Trauma and Analysis Using Proposed New Classification for Ocular Adnexal Injuries. Beyoglu Eye J 2021; 6(2): 102-107.

Address for correspondence: Manisha Singh, MD. Department of Ophthalmology, Gajra Raja Medical College, Gwalior, India

Phone: 8349491509 E-mail: bj.manisha.ms@gmail.com

Submitted Date: January 15, 2021 Accepted Date: March 25, 2021 Available Online Date: June 08, 2021

${ }^{\circ}$ Copyright 2021 by Beyoglu Eye Training and Research Hospital - Available online at www.beyoglueye.com OPEN ACCESS This work is licensed under a Creative Commons Attribution-NonCommercial 4.0 International License. 
trauma causing injury to the ocular adnexal structures can lead to ocular morbidity, such as a cosmetic blemish, permanent facial disfigurement, watering, mechanical entrapment of tissue or fat within a fracture, loss of function due to proptosis, or restricted movement. The frequency of trauma to the ocular adnexa associated with ophthalmic manifestations and consequent morbidity merits a comprehensive classification of adnexal injuries. This study was an examination of the details of mechanical ocular trauma that included an assessment of adnexal injuries in order to create a new, more detailed classification.

\section{Methods}

The ethics committee of Gajra Raja Medical College, Gwalior, M.P, India (9I/IEC-GRMC/2018) granted approval for the study and the research was conducted in accordance with the Declaration of Helsinki.

Data were collected retrospectively over a period of 6 months (January I-June 30, 2018) at a tertiary care center in Gwalior, India. The case details of 600 patients with a mechanical ocular trauma who were aged 18-70 years were analyzed. A complete ophthalmic examination, including a visual acuity assessment, anterior and posterior segment examination, as well as a systemic examination was performed for all of the patients. Any required surgery was performed within
36 hours from the time of injury; those who did not require surgery were treated conservatively with medication (Figs. I, 2). The demographic details, mode of injury, and the types and sub-types of ocular injury with a special emphasis on adnexal injuries, were studied. The cases were divided into 4 age groups of $<20,20-39,40-59$, and $\geq 60$ years to assess the age distribution of the injuries (Table I). To study the mode of injury, all 600 cases were categorized into 5 groups on the basis of the reported etiology: traffic accident, single-level fall, fall from height, assault, and other (Table 2). The injuries were also classified as an open globe or closed globe injury using the Birmingham Eye Trauma Terminology (BETT) system. A new proposed classification system was used to categorize adnexal injury cases, since the BETT system does not account for this type of injury. Ocular adnexal injuries comprised categories of injuries to the eyelid, conjunctiva, lacrimal system, and the orbit, which were further subdivided according to the specific characteristics of the injury (Fig. 3).

\section{Results}

This study included a total of 600 cases of mechanical ocular trauma. A male preponderance was observed, with a male to female ratio of $2.1: 1$ (male: $68.6 \%, n=4 \mid 2$; female: $31.4 \%$, $\mathrm{n}=188$ ). The majority of the patients were in the 20-39 age group ( $48.8 \%$, $(n=293)$, followed by the $40-59$ group $(26.4 \%$,

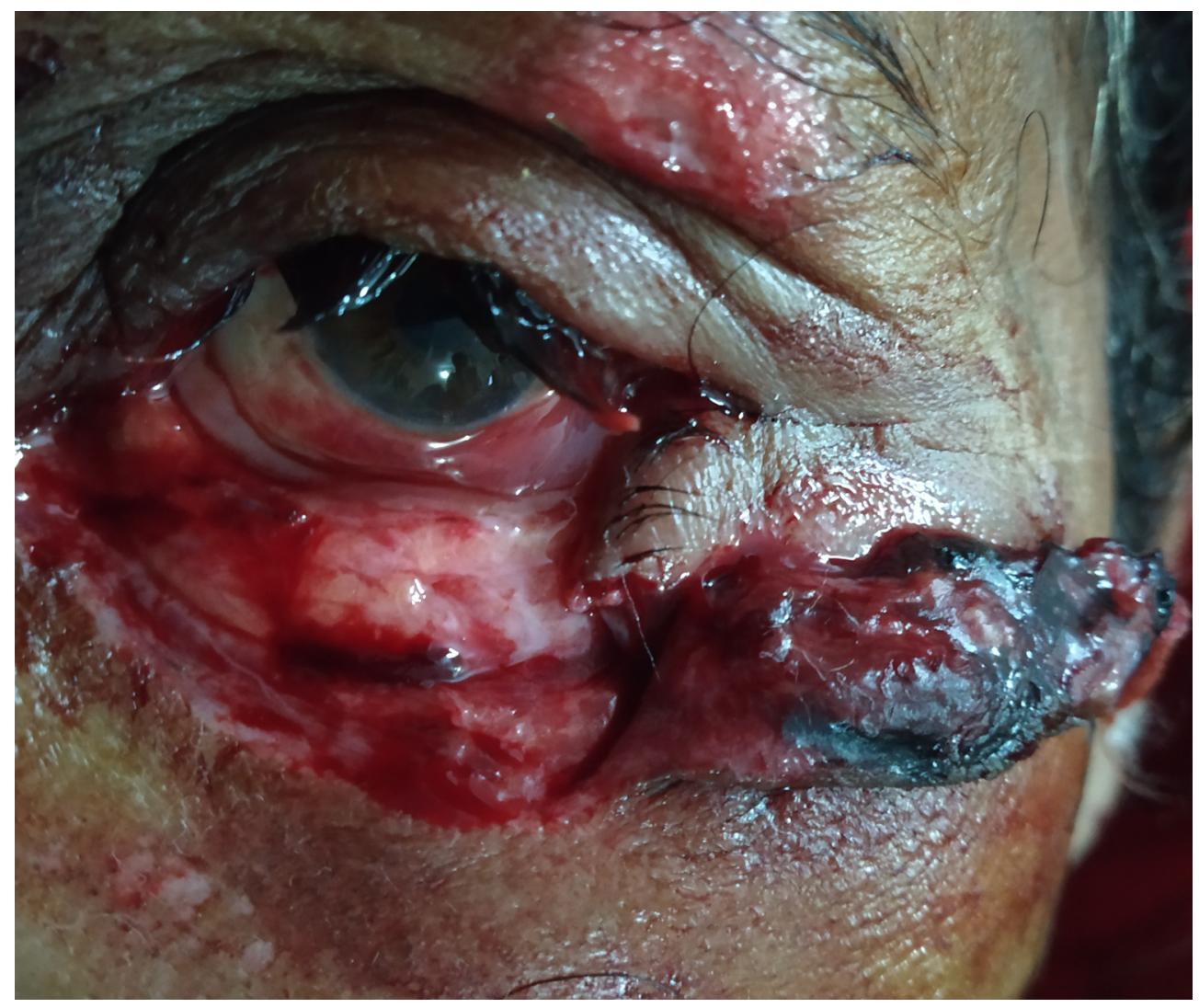

Figure I. A lid laceration before suturing. 


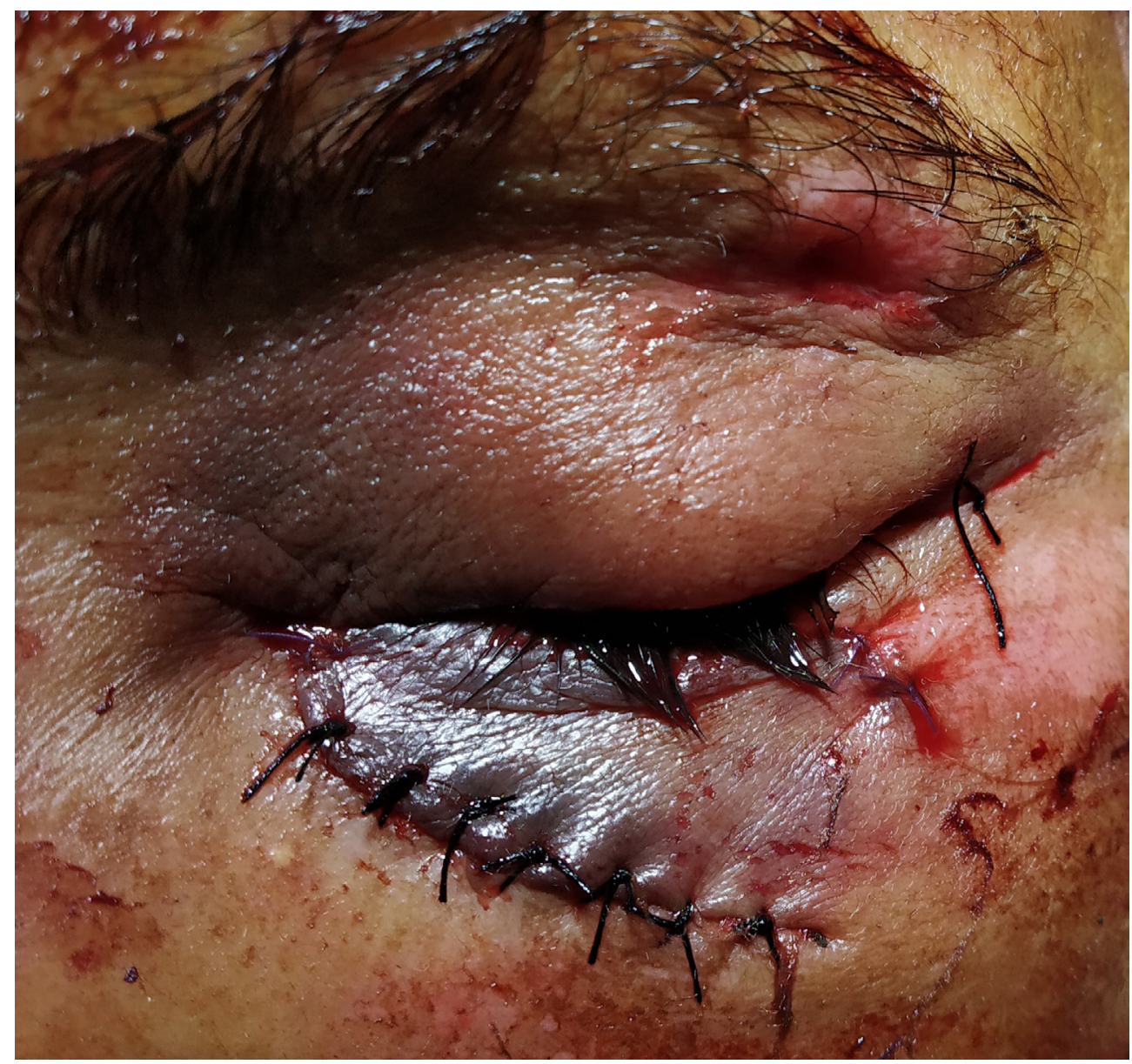

Figure 2. The same lid laceration after suturing.

Table I. Age distribution of mechanical ocular trauma

\begin{tabular}{lcc} 
Age group & Cases $(\mathbf{n})$ & Percentage (\%) \\
\hline$<20$ years & 101 & 16.8 \\
$20-39$ years & 293 & 48.8 \\
$40-59$ years & 158 & 26.4 \\
$\geq 60$ years & 48 & 8 \\
Total & 600 & 100 \\
\hline
\end{tabular}

Table 2. Mode of injury

\begin{tabular}{lcc} 
Etiology & Cases (n) & Percentage (\%) \\
\hline Road traffic accident & 396 & 66 \\
Single-level fall & 75 & 12.5 \\
Fall from height & 61 & 10.1 \\
Assault & 42 & 7 \\
Others & 26 & 4.3 \\
Total & 600 & 100 \\
\hline
\end{tabular}

$n=\mid 58)$, while the group of those $\geq 60$ years of age accounted for the smallest number of cases $(8 \%, n=48)$ (Table I). A road traffic accident was the leading cause of mechanical ocular trauma $(66 \%, n=396)$, followed by a single-level fall $(12.5 \%, n=75)$, and a fall from a height $(10.1 \%, n=6 I)$ (Table 2). A closed globe injury was present in $5.6 \%(n=34)$ of the study cases and an open globe injury was seen in $4.3 \%$ $(n=26)$. The great majority, $90 \%(n=540)$, of the cases were adnexal injuries. Among them, eyelid injuries were present in 532 cases, conjunctival injuries were observed in 427 cases, and there were 5 cases each of lacrimal system injuries and orbital injuries.

The injuries were considered not merely a single type of injury, but in association with I or more types of ocular adnexal injury. The distribution of the cases according to the proposed new classification of adnexal injuries is presented in Table 3. The most common forms of adnexal injury were eyelid edema $(44 \%, n=264)$ and eyelid laceration $(30.3 \%$, $\mathrm{n}=182$ ). Injury to the canaliculi was recorded in 5 cases. No instance of injury to the lacrimal gland or lacrimal sac was seen in this study. There were 4 cases of a lateral orbital 


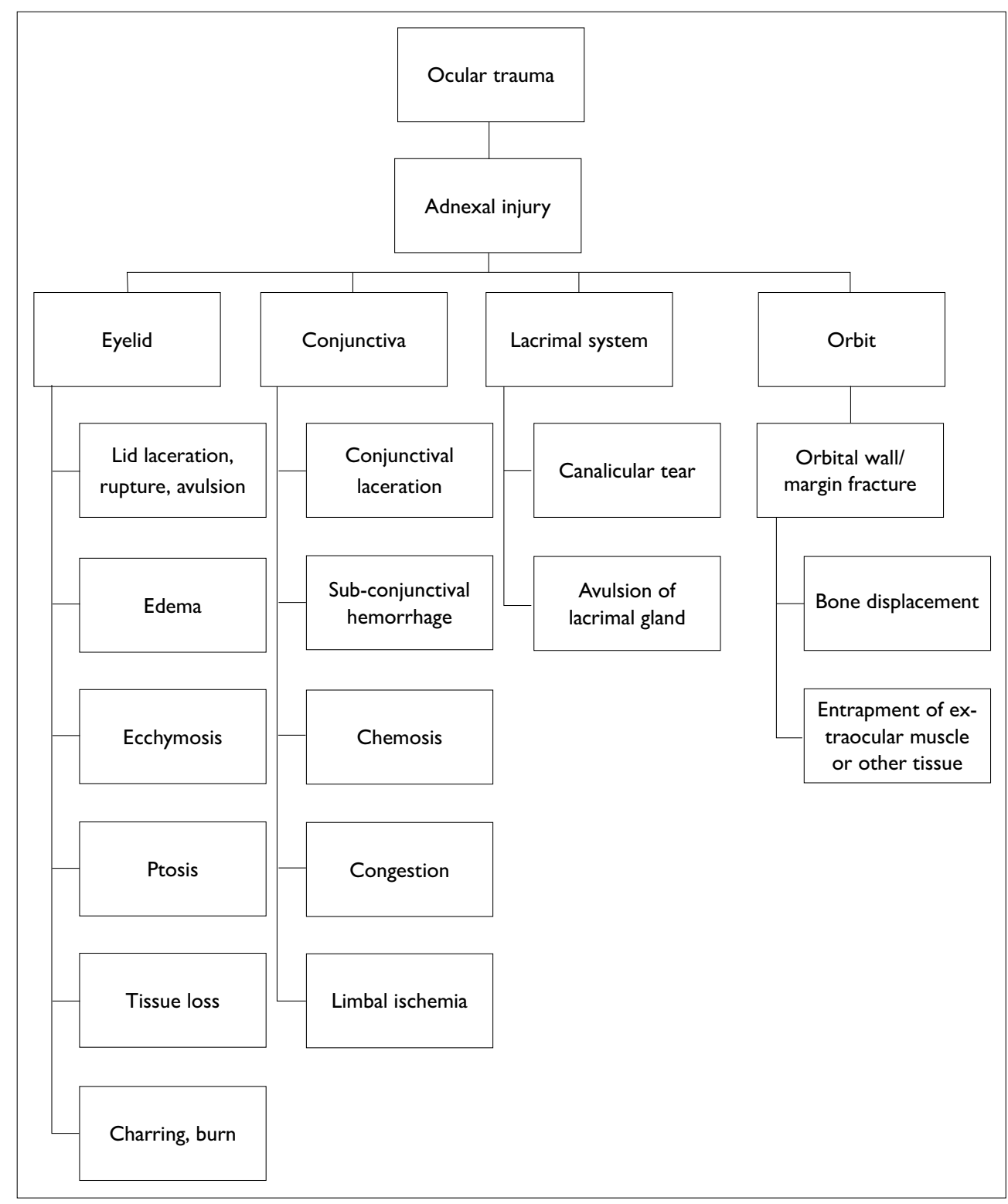

Figure 3. Proposed classification for adnexal injuries.

wall fracture and I case of an inferior wall fracture. None of the patients presented with an orbital wall fracture, displacement of bone, or entrapment of any tissue (Table 3).

Vision was markedly affected in the open globe injuries, varying from counting fingers to hand movement. The adnexal injury cases in this study had a best corrected visual acuity ranging between $20 / 200$ and $20 / 40$, with a mean visual acuity of 0.67 logarithm of the minimum angle of resolution (20/94). The adnexal injuries consisting of lid laceration, rupture, or avulsion in $30.3 \%(n=182)$, ptosis in $2 \%(n=12)$, tissue loss in $3.6 \%(n=18)$, canalicular laceration in $0.8 \%$ $(n=5)$, and orbital wall fracture in $0.8 \%(n=5)$ required surgical management. The complications observed were epiphora in $0.16 \%(n=I)$ and eyelid coloboma in a case of excessive eyelid tissue loss $0.3 \%(n=2)$.

\section{Discussion}

Among the 600 cases reviewed for this study, only $10 \%$ of the injuries could be classified using the BETT classification. While the conventional classification system has been valuable, it is limited. Kuhn et al. $(2,3)$ proposed the BETT classification system in 1996 and divided ocular trauma into open and closed globe injuries. Adnexal injuries were not included. The Ocular Trauma Score (OTS) was developed in the early 2000 s to provide a simple system to determine a visual prognosis in cases of an open globe injury $(4,5)$. There was a proposal in $\mathbf{2 0 0 9}$ that "ocular trauma" include the ocular adnexa, i.e., the eyelids, conjunctiva, lacrimal apparatus, and the orbit, in addition to the globe (6). In 2014, Xiao et al. (7) classified mechanical injuries as ocular adnexa 
Table 3. Adnexal injuries

\begin{tabular}{lcc} 
Adnexal injuries & Cases (n) & Percentage (\%) \\
\hline Eyelid & 182 & 30.3 \\
Lid laceration, rupture, avulsion & 264 & 44 \\
Lid edema & 180 & 30 \\
Ecchymosis & 12 & 2.4 \\
Ptosis & 18 & 3.6 \\
Tissue loss & 0 & 0 \\
Charring, burn & & \\
Conjunctiva & 10 & 1.6 \\
Conjunctival laceration & 164 & 27.3 \\
Chemosis & 108 & 18 \\
Sub-conjunctival hemorrhage & 145 & 24.1 \\
Congestion & 0 & 0 \\
Limbal ischemia & & 0.8 \\
Lacrimal apparatus & 5 & 0 \\
Canalicular laceration & 0 & 0.8 \\
Avulsion of lacrimal gland & 5 & \\
Orbit & 0 & \\
Orbital wall/margin fracture & & \\
Displacement of bone & & \\
Entrapment of extraocular & & \\
muscle or other tissue & & \\
\hline & & \\
\hline
\end{tabular}

injury, eyeball injury, and retained foreign body injury. They divided adnexal injuries into the categories of orbital injury, eyelid injury, lacrimal apparatus injury, extraocular muscle injury, and other. Shukla et al. (8) created a well-structured classification for ocular trauma that included wide range of injuries in 2017. They separated ocular trauma into mechanical and non-mechanical injuries, and the mechanical injuries were categorized as a globe injury, destructive globe injury, or an adnexal injury. However, a proper classification system for ocular adnexal injuries remained to be defined. Shukla et al. (9) suggested a classification for adnexal injuries in 2009. This consideration has a significant impact, as seen in other studies of ocular trauma $(10,11)$. Singh et al. (I2) observed that early intervention led to better results: It helped to prevent infection, and restoration of the integrity of the ocular structures led to a cosmetically preferable scar and better visual acuity. Both open globe injuries and closed globe injuries can directly affect visual outcome. Adnexal injuries are a very common sequela of mechanical ocular trauma but generally do not affect the visual outcome. Complications observed in our study after surgical intervention within 36 hours were epiphora in $0.16 \%(n=1)$ and notching of the lid in a case of excessive eyelid tissue loss in $0.3 \%(n=2)$.
Late intervention may result in restricted motility of the eye, diplopia, or a cosmetically poor scar. The results of our study suggest that neglecting adnexal injuries can lead to a longer period of healing, severe complications, or permanent disfigurement. It is therefore prudent to include trauma to the ocular adnexa in a comprehensive, well-structured classification system of mechanical ocular trauma. The majority of the mechanical trauma cases in our study involved the ocular adnexa and did not qualify for categorization as either an open globe or a closed globe injury (10). A surgical repair must be performed with a layered approach in cases of deep wounds. Otherwise, it can lead to late complications, such as notching at the lid margin, overlapping, or deformities of the lid (I3). An early and complete ophthalmic examination is essential to thoroughly assess the localization and extent of the injury, identify any associated injuries, and determine the most appropriate management $(14,15)$.

\section{Conclusion}

The proposed classification system offers a simple yet thorough means to assess ocular injuries upon presentation. Adoption of this more comprehensive classification that includes adnexal injuries would assist clinicians to provide optimal management and better outcomes.

\section{Disclosures}

Ethics Committee Approval: The study protocol was reviewed and approved by the institutional ethics committee of Gajra Raja Medical College, Gwalior, M.P, India (9//IEC-GRMC/2018). This study was conducted in accordance with the Declaration of Helsinki.

Peer-review: Externally peer-reviewed.

Conflict of Interest: None declared.

Authorship Contributions: Involved in design and conduct of the study (AS, MS); preparation and review of the study (MS, AS, $A G)$; data collection (MS, AG); and statistical analysis (MS, AG).

\section{References}

I. Katz J, Tielsch JM. Lifetime prevalence of ocular injuries from Baltimore Eye Survey. Arch Ophthalmol 1993; I I :I564-8. [CrossRef]

2. Kuhn F, Morris R, Witherspoon CD, Heimann K, Jeffers JB, Treister G. A standardized classification of ocular trauma. Ophthalmology 1996; 103:240-3. [CrossRef]

3. Kuhn F, Morris R, Witherspoon CD, Mester V. The Birmingham Eye Trauma Terminology system(BETTS). J Fr Ophtalmol 2004;27:206-10. [CrossRef]

4. El Shtewi M, Shishko MN, Purohit GK. Road traffic accidents and ocular trauma: experience at Tripoli Eye Hospital, Libya. Community Eye Health 1999; 12:1 I-2.

5. Kuhn F, Maisiak R, Mann L, Mester V, Morris R, Witherspoon $\mathrm{CD}$, et al. The ocular trauma score (OTS). Ophthalmol Clin N Am 2002;15:163-5. [CrossRef] 
6. Saxena R, Sinha R, Purohit A, Dada T, Vajpayee RB, Azad RV. Pattern of pediatric ocular trauma in India. Indian J Pediatr 2002;69:863-7. [CrossRef]

7. Xiao JH, Zhang MN, Li SY, Jiang $\mathrm{CH}$, Jiang $\mathrm{H}$, Zhang $\mathrm{Y}$, et al. A new classification for epidemiological study of mechanical eye injuries. Chin J Traumatol 20I4; 17:35-7.

8. Shukla B, Agrawal R, Shukla D, Seen S. Systematic analysis of ocular trauma by a new proposed ocular trauma classification. Indian J Ophthalmol 2017;65:719-22 [CrossRef]

9. Shukla A, Sıngh M, Kumar A, Sisodia P, Kujur R, Gupta P . A new proposed classification for ocular adnexal injuries - A way to analyze and systematically describe adnexal injuries. CEOTI 2020;2:43-6.

10. Oum BS, Lee JS, Han YS. Clinical features of ocular trauma in emergency department Korean J Ophthalmol 2004; 18:70-8.

II. Schmidt GW, Broman AT, Hindman HB, Grant MP. Vision survival after open globe injury predicted by classification and regression tree analysis. Ophthalmology 2008; I 15:202-9. [CrossRef]

12. Singh K, Mutreja A, Bhattacharyya M, Dangda S. Epidemiology and Implications of ocular trauma admitted to a tertiary care hospital in North India. US Opthalmic Rev 2017;10:64-8. [CrossRef]

13. Roy I S, Mitra J N, Saha P L, Sen S C. Management of lacerated injuries of the eye and its adnexa. Indian J Ophthalmol 1984;32:293-4

14. Goldberg RA. Orbital and adnexal trauma. Curr Opin Ophthalmol 1992;3:686-94. [CrossRef]

15. Madavi BS, Vasana IG. Ocular manifestations of head injury in trauma cases. Glob Res Anal 2013;2:184-5. 